Ekspansi: Jurnal Ekonomi, Keuangan, Perbankan dan Akuntansi

ISSN (Online): 2580-7668 ISSN (Print): 2085-5230

Vol. 11, No. 2 (November 2019), Hal. 223 - 230

\title{
PENGARUH INTELLECTUAL CAPITAL TERHADAP PRODUKTIVITAS KERJA PEGAWAI DI PEMERINTAH DAERAH
}

\author{
Lili Indrawati ${ }^{1}$, Etti Ernita Sembiring ${ }^{2}$ \\ ${ }^{1,2}$ Jurusan Akuntansi, Politeknik Negeri Bandung, Bandung, Indonesia \\ Email Korespondensi: indratoriq@gmail.com
}

\begin{abstract}
The purpose of this research is to analyze and prove the role of intellectual capital against employee productivity in local government. The research was carried out at the Cimahi local government,Bandung Local Government and West Java Province. The number of respondent was 128 employees from 10 accounting entity in Bandung city, 10 accounting entity in Cimahi city and 11 accounting entity in West Java province. The entity which are used as sample in this research which have revenue and expenditure. The research method used is purposive sampling. To analyze the data from the respondent is WarpPLS. The research shows that intellectual capital does affect positive significantly the employee productivity of local government.
\end{abstract}

Keywords: Intellectual Capital, Employee Productivity, Local Government

Abstrak: Penelitian ini bertujuan untuk menguji pengaruh modal intektual terhadap produktivitas kerja pegawai. Modal intelektual yang diuji terbagi menjadi tiga yaitu kompetensi pegawai, komitmen dan pengendalian kerja. Penelitian ini dilakukan di Kota Cimahi, Kota Bandung dan Provinsi Jawa Barat. Peneliti mengumpulkan data dengan menyebarkan kuesioner sebanyak 128 kepada pegawai berasal dari 10 dinas di Kota Bandung, 11 dinas di Kota Cimahi dan 11 dinas di provinsi Jawa Barat. Teknik pengambilan sampel yang digunakan adalah metode purposive sampling. Satuankerja yang dijadikan sampel adalah satuan kerja yang memiliki pendapatan dan belanja. Alat analisis data yang digunakan adalah aplikasi WarpPLS. Hasil penelitian menunjukkan bahwa modal intelektual berpengaruh positif terhadap produktivitas kerja pegawai. Apabila modal intelektual meningkat maka produktivitas kerja pegawai juga meningkat dan sebaliknya jika modal intelektual menurun maka produktivitas juga ikut menurun.

Kata Kunci: Modal intelektual, Produktivitas kerja pegawai, Pemerintah Daerah

DOI: $10.35313 /$ ekspansi.v11i2.1559

Riwayat Artikel:

Diterima: 30 - $09-2019$

Direvisi: $18-11-2019$

Disetujui: $24-11-2019$ 


\section{PENDAHULUAN}

Sumber daya manusia merupakan aset penting bagi perusahaan baik sektor swasta maupun sektor publik. Fitz-enz (2000) menyatakan kunci untuk menjaga kelangsungan sebuah perusahaan yang menguntungkan atau perekonomian bangsa yang sehat adalah produktivitas human capital yang dimiliki. Aspek dari human capital yang menjadi intangible asset bagi perusahaan adalah modal intelektual. Seseorang dikatakan memiliki modal intelektual baik jika seseorang itu memiliki komitmen, kompetensi dan pengendalian pekerjaan (Burr\&Girardi, 2002; Maghfiroh,2010). Modal intelektual yang memadai akan mendorong produktivitas pegawai sehingga menguntungkan perusahaan. Namun yang terjadi adalah pihak manajemen masih kesulitan menciptakan sumber daya manusia yang memiliki modal intelektual yang memadai.

Faktor sumber daya manusia (intellectual capital) merupakan faktor yang sangat penting untuk meningkatkan produktivitas pegawai. Beberapa penelitian yang sudah dilakukan membuktikan bahwa modal intelektual memiliki pengaruh positif terhadap produktivitas. Seperti yang dilakukan oleh Fajar, Dwi Junita (2018), Michael Chidiebere Ekwe (2013) dan Agung Nugroho (2018) yang melakukan penelitian untuk membuktikan adanya pengaruh positif terhadap produktivitas dan hasilnya menunjukkan dukungan terhadap pernyataan tersebut. Apabila modal intelektual meningkat maka produktivitas juga akan meningkat. Penelitian ini menguji pengaruh modal intelektual terhadap produktivitas kerja pegawai. Perbedaan penelitian ini dengan penelitian sebelumnya adalah pada jenis sektor. Jika penelitian sebelumnya meneliti pada sektor swasta maka penelitian ini meneliti pada sektor pemerintah yang memiliki karakteristik berbeda dibandingkan dengan sektor swasta. Selain itu itu entitas yang menjadi fokus penelitian hanya entitas yang memiliki pendapatan dan belanja saja.

Nazier (2009) menyatakan masih banyak tenaga akuntansi di sektor pemerintahan baik sebagai penentu kebijakan maupun sebagai pelaksana kebijakan yang belum memiliki pemahaman mengenai akuntansi pemerintahan. Dampak dari ketidakpahaman ini adalah sampai saat ini masih banyak Pemda yang melakukan kesalahan dalam pencatatan dan penyimpangan dalam penyajian laporan keuangan. Temuan BPK pada semester I tahun 2018 mengungkapkan bahwa masih banyak terjadi kesalahan pencatatan akuntansi sehingga penyajiannya tidak sesuai dengan SAP dan juga tidak didukung oelh bukti yang kuat. Beberapa temuan mengungkapkan bahwa piutang belum disajikan sebesar nilai bersih yang dapat direalisasikan, dan pencatatan persediaan yang tidak sesuai dengan kebijakan akuntansi pemda yang bersangkutan dan masih banyak temuan lainnya. Selain itu temuan BPK mengungkapkan juga kelemahan dalam sistem pengendalian akuntansi dan pelaporan. (Ikhtisar Hasil Pemeriksaan Semester I tahun 2018 atas laporan Keuangan Pemerintah Daerah se Indonesia). 


\section{TINJAUAN PUSTAKA}

Intellectual Capital atau disebut juga Human Capital, merupakan sumber daya terpenting bagi setiap organisasi yang bersifat global dan berbasis pengetahuan/keterampilan diseluruh dunia. Seperti yang dituturkan oleh Fitz-enz (2000) bahwa kunci untuk menjaga kelangsungan sebuah perusahaan yang menguntungkan atau perekonomian bangsa yang sehat adalah produktivitas human capital yang dimiliki. Selanjutnya yang menjadi perhatian organisasi adalah bagaimana mengendalikan dan memanfaatkan sumber daya ini sehingga akhirnya organisasi dapat mewujudkan tujuan strategisnya. Burr \& Girardi (2002) menyatakan bahwa "modal intelektual adalah interaksi antara kompetensi, komitmen dan pengendalian dari karyawan”. Pola interaksi dari kompetensi, komitmen dan pengendalian pekerjaan dalam membentuk intellectual capital dapat dilihat pada gambar di bawah ini.

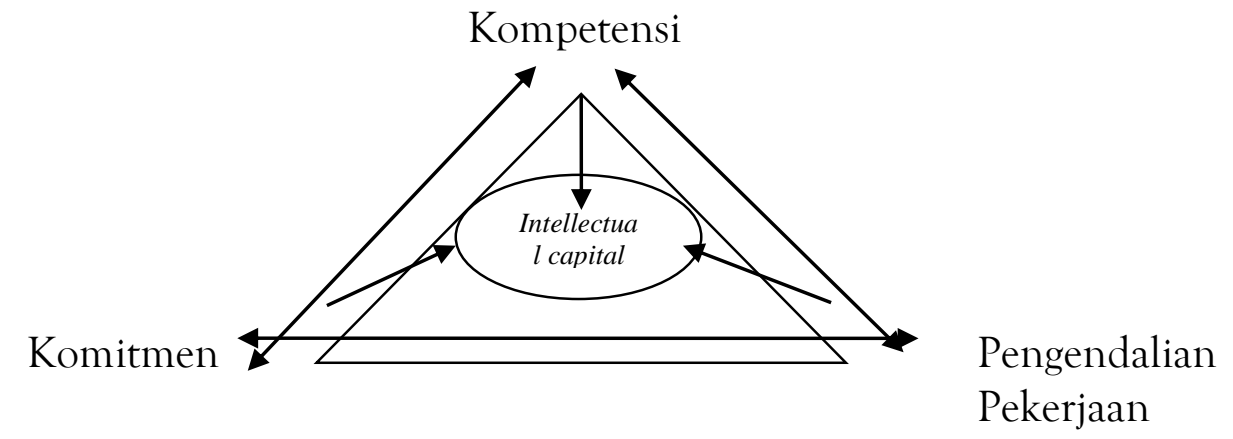

Sumber: Burr \& Gerardi (2002)

Dari pola interaksi di atas terlihat bahwa kompetensi dan komitmen serta pengendalian kerja yang ada pada pegawai, jika dipadukan dengan baik dan benar, akan mampu menciptakan nilai yang tinggi bagi suatu organisasi. Kompetensi akan menjadi acuan dan dasar bagi manajemen untuk mengelola human capital, karena secara efektif kompetensi menerjemahkan visi dan tujuan strategis ke dalam prilaku yang teramati atau tindakan yang harus dilakukan oleh para pegawai.

Selanjutnya komitmen yang diperoleh dari kekuatan emosional pegawai yang menyenangkan akan dapat mengatasi kelelahan emosional dan sikap negatif serta stress melalui praktek keterlibatan kerja yang berfokus pada tingkat otonomi pekerja dan pengaturan diri atau pengendalian pekerjaan (Ulrich,1998). Pengendalian pekerjaan atau otonomi kerja adalah pengembangan aktivitas pekerja pada pekerjaan yang mengarah pada perbaikan efektivitas operasi dan kepuasan kerja, karena pekerja dapat menggunakan semua kemampuan yang dimiliki secara leluasa dan penuh (Newstorn \& Davis; 2004).

Produktivitas kerja karyawan menurut Gaol (2014)merupakan prestasi karyawan di lingkungan kerjanya. Produktivitas yang tinggi merupakan cerminan pegawai yang merasa puas akanpekerjaannya dan akan memenuhi semua kewajibannya sebagai pegawai.Penelitian ini menggunakan faktor pendidikan, disiplin kerja dan pengalaman kerja untuk mengukur produktivitas.Pendidikan disini dapat berarti pendidikan formal maupun no formal. Tingginya kesadaran akan pentingnya produktivitas akan mendorong pegawai yang bersangkutan melakukan tindakan yang produktif. Pada 
umumnya orang yang mempunyai pendidikan lebih tinggi akan mempunyai wawasan yang lebih luas terutama penghayatan akan arti pentingnya produktivitas. Disiplin kerja merupakan kunci keberhasilan dalam mencapai tujuan, yang pada akhirnya akan berpengaruh pada produktivitas. Pengalaman kerja seseorang akan menunjukkan tingkat pengetahuan dan pemahaman untuk menjalankan tugas yang dihadapi.

Berdasarkan kajian di atas maka hipotesis penelitian yang disusun adalah Modal Intelektual berpengaruh signifikan terhadap produktivitas kerja pegawai.

\section{METODE PENELITIAN}

Unit kerja yang ada di pemerinatah daerah digunakan sebagai populasi dalam penelitian ini yaitu di pemerintah daerah Kota Cimahi, Kota Bandung dan Dinas di Prodinsi Jawa Barat. sedangkan sampel penelitian menggunakan Teknik purposive sampling, yaitu hanya terbatas pada unit tertentu yang dapat memberikan informasi dengan kriteria yang sudah ditentukan (Sekaran, 2006), yaitu satuan kerja yang mempunyai pendapatan dan belanja saja. Sedangkan metode pengumpulan data adalah penelitian lapangan (field research), sumber data yang digunakan dan dianalisis adalah jenis data primer (primary data). Data primer merupakan sumber data penelitian yang diperoleh secara langsung dari sumber asli tanpa melalui perantara (Indriantoro \& Supomo, 1999)

Dalam penelitian ini, variabel yang diteliti adalah modal intelektual (intellectual capital) dan produktivitas kerja pegawai. Variabel intellectual capital merupakan variabel independen, sedangkan variabel dependennya adalah produktivitas kerja pegawai. Variabel-variabel ini akan diukur dengan instrumen pengukuran dalam bentuk kuesioner yang bersifat tertutup yang memenuhi persyaratan skala likert. Untuk setiap pilihan jawaban diberi skor, dan skor yang diperoleh mempunyai tingkat pengukuran ordinal. Indikator Intellectual Capital (kompetensi, komitmen dan pengendalian kerja) akan menggunakan dari Spencer \& Spencer (1993), sedangkan indikator produktivitas kerja akan menggunakan indikator dari Sedarmayanti (2009).

Pengujian akan dilakukan dengan menggunakan analisis model dengan WarpPLS, pada perangkat ini analisis data dilakukan dengan pendekatan non parametris. Penggunaan aplikasi ini karena mampu memperhitungkan keseluruhan model secara bersamaan dalam satu waktu, dan bisa menghitung nilai probabilitas (P-value) berdasarkan prosedur distribusi netral non parametrik (Kock,2017), serta mampu menghitung dengan skala data nominal. Hal ini sangat penting karena indikator variabel yang terdapat dalam model ini menggunakan data dengan bentuk ordinal yang dalam tingkatan skala data berada di atas data nominal. Selain itu software ini memiliki perhitungan kecukupan model atau yang sering dikenal dengan nama Goodness of Fit (GoF) atau kalau di WarpPLS dikenal dengan nama Model Fit and quality indices.

Selanjutnya akan dilakukan uji hipotesis untuk menetapkan apakah hipotesis yang diajukan di dukung oleh fakta yang dikumpulkan dan dianalisa dalam proses pengujian data. Pengujian hipotesis akan menggunakan data sampel dengan tingkat signifikansi yang digunakan sebesar 5\% $(\alpha=5 \%)$. Tingkat signifikansi ini menggambarkan 
kemungkinan peneliti melakukan kesalahan tipe I, yaitu menolak hipotesis nol, padahal hipotesis nol benar (Anshori \& Iswati, 2009). Dengan kata lain tingkat signifikansi menggambarkan kemungkinan peneliti untuk menolak atau mendukung hipotesis. Hipotesis yang diuji secara statistik adalah hipotesis nol, dengan kriteria pengambilan keputusan berdasarkan tingkat signifikansi, yaitu sebagai berikut:

- Jika nilai probabilitas lebih kecil dari nilai $\alpha=0.05$, maka $\mathrm{H}_{0}$ ditolak dan $\mathrm{Ha}$ diterima

- Jika nilai probabilitas lebih besar dari nilai $\alpha=0,05$, maka $\mathrm{H}_{0}$ tidak ditolak dan $\mathrm{Ha}$ tidak diterima

\section{HASIL DAN PEMBAHASAN}

Penelitian ini menggunakan alat bantu aplikasi WarpPLS. Setelah data penelitian dikumpulkan maka tahap berikutnya adalah tahap tabulasi data. Data dikelompokkan sesuai indikator, selanjutnya data tersebut diolah menggunakan program aplikasi WarpPLS. Tahap awal analisis adalah adalah menguji goodnes of fit model (kecukupan model), Model dikatakan fit jika nilai yang dihasilkan berada pada nilai cut of value, berikut adalah tabel hasil Goodnes of fit model .

Tabel 2. Goodnes of fit model

\begin{tabular}{|l|l|l|l|l|l|}
\hline \multirow{2}{*}{ Kriteria } & \multirow{2}{*}{ Nilai } & \multirow{2}{*}{ P-value } & \multicolumn{2}{l|}{ Cut-of Value } & Keterangan \\
\cline { 4 - 7 } & & & Acceptable & Ideal & \\
\hline $\begin{array}{l}\text { Average path coefficient } \\
\text { (APC) }\end{array}$ & 0,698 & $<0,001$ & - & 0,05 & Model Fit \\
\hline Average R-squared (ARS) & 0,488 & 0,035 & - & 0,05 & Model Fit \\
\hline $\begin{array}{l}\text { Average adjusted R-squared } \\
\text { (AARS) }\end{array}$ & 0,484 & 0,041 & - & 0,05 & Model Fit \\
\hline $\begin{array}{l}\text { Average full collinearity } \\
\text { VIF (AFVIF) }\end{array}$ & 1.728 & - & $<=5$ & $<=3,3$ & Model Fit \\
\hline $\begin{array}{l}\text { Tenenhaus GoF } \\
\text { (GoF)=0.217 }\end{array}$ & 0,464 & - & $\begin{array}{l}\text { small }>=0,1 ; \text { medium }>=0,25 ; \\
\text { large }>=0,36\end{array}$ & Model Fit \\
\hline $\begin{array}{l}\text { Sympson's paradox ratio } \\
\text { (SPR) }\end{array}$ & 1 & - & $>=0,7$ & 1 & Model Fit \\
\hline $\begin{array}{l}\text { R-squared contribution } \\
\text { ratio (RSCR) }\end{array}$ & 1 & - & $>=0,9$ & 1 & Model Fit \\
\hline $\begin{array}{l}\text { Statistical suppression ratio } \\
\text { (SSR) }\end{array}$ & 1 & - & $>=0,7$ & - & Model Fit \\
\hline $\begin{array}{l}\text { Nonlinear bivariate } \\
\text { causality direction ratio } \\
\text { (NLBCDR) }\end{array}$ & 1 & - & $>=0,7$ & - & Model Fit \\
\hline
\end{tabular}

(Sumber : data diolah)

Berdasarkan tabel di atas, terlihat bahwa model dalam kondisi fit sehingga dapat dilakukan analisis berikutnya yaitu untuk mencari pengaruh modal intelektual terhadap produktivitas kerja pegawai. 
Untuk melihat apakah indikator yang digunakan memang memiliki pengaruh terhadap variabel laten yang diwakili oleh Intellectual Capital dan Produktivitas Kerja Pegawai, digunakan hasil perhitungan indicator weight dengan kriteria sebagai berikut:

1. Jika nilai P-value $<0,05$ dan nilai VIF $<2,5$ maka indikator dapat digunakan dalam perhitungan.

2. Jika nilai P-value > 0,05 dan nilai VIF > 2,5 maka indikator dapat dikeluarkan dari perhitungan.

Berdasarkan hasil alat analisis diperoleh indikator-indikator yang dapat digunakan karena memenuhi kriteria sebagai berikut:

Tabel 3 Indicator weight

\begin{tabular}{|l|l|l|l|l|}
\hline Indikator & \multicolumn{1}{|c|}{ P-value } & VIF & \multicolumn{1}{|c|}{ Keterangan } & Kesimpulan \\
\hline IC_2 & 0,009 & 1,741 & P-value $<0,05$ dan nilai VIF $<2,5$ & Digunakan \\
\hline IC_3 & 0,032 & 2,168 & P-value $<0,05$ dan nilai VIF $<2,5$ & Digunakan \\
\hline IC_4 & 0,013 & 2,452 & P-value $<0,05$ dan nilai VIF $<2,5$ & Digunakan \\
\hline IC_6 & 0,019 & 1,523 & P-value $<0,05$ dan nilai VIF $<2,5$ & Digunakan \\
\hline IC_7 & 0,012 & 1,833 & P-value $<0,05$ dan nilai VIF $<2,5$ & Digunakan \\
\hline IC_8 & 0,024 & 1,618 & P-value $<0,05$ dan nilai VIF $<2,5$ & Digunakan \\
\hline IC_9 & 0,021 & 1,782 & P-value $<0,05$ dan nilai VIF $<2,5$ & Digunakan \\
\hline IC_10 & 0,005 & 2,811 & P-value $<0,05$ dan nilai VIF $<2,5$ & Digunakan \\
\hline PK_1 & 0,035 & 1,795 & P-value $<0,05$ dan nilai VIF $<2,5$ & Digunakan \\
\hline PK_3 & 0,025 & 1,91 & P-value $<0,05$ dan nilai VIF $<2,5$ & Digunakan \\
\hline PK_4 & 0,014 & 2,005 & P-value $<0,05$ dan nilai VIF $<2,5$ & Digunakan \\
\hline PK_6 & 0,036 & 1,599 & P-value $<0,05$ dan nilai VIF $<2,5$ & Digunakan \\
\hline PK_8 & 0,038 & 1,442 & P-value $<0,05$ dan nilai VIF $<2,5$ & Digunakan \\
\hline PK_11 & 0,012 & 2,229 & P-value $<0,05$ dan nilai VIF $<2,5$ & Digunakan \\
\hline PK_12 & 0,006 & 2,403 & P-value $<0,05$ dan nilai VIF $<2,5$ & Digunakan \\
\hline PK_13 & 0,047 & 1,41 & P-value $<0,05$ dan nilai VIF $<2,5$ & Digunakan \\
\hline PK_14 & 0,028 & 1,771 & P-value $<0,05$ dan nilai VIF $<2,5$ & Digunakan \\
\hline
\end{tabular}

(Sumber : data diolah)

Berdasarkan tabel di atas dapat dilihat Indikator yang dapat digunakan dalam perhitungan untuk IC adalah IC2, IC3, IC4, IC6, IC7, IC8, IC9, IC10. Sedangkan Indikator yang dapat digunakan untuk PK adalah PK!, PK3, PK4, PK6, PK8, PK11, PK12,PK13, PK14.

Hasil analisis berikutnya adalah menguji pengaruh Intellectual Capital terhadap Produktivitas Kerja Pegawai. Hasilnya dapat dilihat pada bagan dan tabel berikut ini :

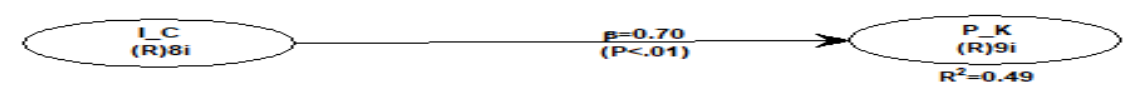

IC diwakili sebanyak 8 indikator dan PK diwakili oleh 9 indikator. Dari gamabr tersebut terlihat bahwa IC berpengaruh positif terhadap PK, hal ini menyatakan bahwa setiap peningkatan IC akan meningkatkan PK dan demikian juga jika terjadi penurunan pada IC akan berakibat menurunnya PK.

Tabel 4. Uji pengaruh Intellectual Capital terhadap Produktivitas Kerja Pegawai

\begin{tabular}{|c|c|c|c|}
\hline Variabel & Koefisien & P-Value & Keterangan \\
\hline I_C $\rightarrow$ P_K & 0,70 & $<0,01$ & Berpengaruh signifikan \\
\hline
\end{tabular}

(Sumber : data diolah) 
Berdasarkan tabel dan bagan di atas dapat dilihat tingkat signifikansi berada di bawah 0,05 maka dapat disimpulkan Intellectual Capital berpengaruh positif terhadap Produktivitas Kerja Pegawai. Hipotesis yang diajukan pada penelitian ini didukung. Hasil penelitian sesuai dengan penelitian Fajar, Dwi Junita (2018), Michael Chidiebere Ekwe (2013), Agung Nugroho (2018) yang menyatakan bahwa modal intelektual mempengaruhi Produktivitas Kerja.

Hasil penelitian yang menunjukkan semakin tinggi Intellectual capital pegawai maka tingkat produktivitas juga semakin tinggi. Pemerintah daerah harus berupaya menciptakan strategi strategi yang dapat meningkatkan intellectual capital pegawainya. Menurut Thamrin (2006) dalam proses modernisasi penting sekali melibatkan pegawai, karena tanpa itu hanya akan dicapai ketidakpastian dan sering kali muncul sikap penolakan yang merintangi pelaksanaan reformasi. Menurut Ahmadi et.al (2011) perlu dilakukan pula pengembangan modal intelektual untuk meningkatkan kinerja. Pengembangan modal intelektual dapat dilakukan dengan pendidikan dan pelatihan, hal ini perlu dilakukan pemerintah daerah dimana proses menjadi pegawai dalam kantor publik tidak berdasarkan kualifikasi dan reabilitas karyawan, melainkan melalui nepotisme atau cara politis. Hal inilah yang membuat mentalitas para karyawan dalam jawatan pemerintah yang menganggap diri mereka memiliki semua keistimewaan sebagai pegawai negeri (Thamrin, 2006). Selanjutnya Thamrin (2006) menyatakan walau kualifikasi baik tanpa didukung teknik informasi dan komunikasi yang menggunakan jaringan struktur klien/server yang baik, maka unit yang bekerja secara desentral tidak bisa dikendalikan, dan mungkin tidak dapat membuat pengolahan data yang memuaskan. Oleh karena itu hanya dengan teknologi seperti ini one stop service terhadap klien dapat terjamin.

\section{PENUTUP}

Penelitian ini dilakukan berdasarkan pada pemikiran bahwa semua pemerintah daerah di Indonesia sudah menerapkan PP 71 tahun2010 tentang SAP, dan sudah menerapkannya hampir lima tahun. Hasil penelitian menunjukkan bahwa intellectual capital berpengaruh positif signifikan terhadap produktivitas kerja pegawai dalam penatausahaan dan pengakuntansian realisasi pendapatan dan belanja. Hasil penelitian ini sesuai dengan penelitian Fajar, Dwi Junita (2018), Michael Chidiebere Ekwe (2013), Agung Nugroho (2018). Keterbatasan dalam penelitian ini adalah responden dibatasi hanya pada satuan kerja yang mempunyai pendapatan dan belanja saja. Namun begitu pada saat ini pemerintah daerah sedang berusaha untuk meningkatkan modal intelektual petugas pelaksana mereka, hal ini terlihat bahwa mereka selalu berusaha untuk selalu meningkatkan kompetensi mereka dengan bimbingan teknis. Peningkatan produktivitas kerja pegawai dapat dilakukan jika para pekerja baik tingkat manajer dan pelaksana memiliki komitmen, kompetensi dan pengendalian kerja untuk menerapkannya secara optimal dan bersungguh-sungguh. 


\section{DAFTAR PUSTAKA}

Agung Nugroho, (2018), Analisis Produktivitas kerja karyawan outsourcing pada PT Siantar Putra Mandiri, Jurnal Analisis Produktivitas..

Ahmadi, Ali Akbar et al. 2011. The Survey of Realationship between Intellectual Capital and Organization Performance within the National Iranian South Oil Company. Interdisciplinary Journal of Contemporary Research in Business. Vol. 3, No. 5.

Anshori, M \& Iswati,S (2009). Buku Ajar Metodologi Penelitian Kuantitatif, Surabaya; Airlangga University Press

Burr, Renu \& Antonia Gerardi.2002. Intellectual Capital: More Than The Interaction of Competence $x$ Commitment, Australian Journal of Management. Vol 27.

Danang, Sunyoto, 2012, Teori, Kuesioner dan Analisis Data Sumber Daya Manusia (Praktik Penelitian), Yogyakarta: CAPS (Center for Academic Publishing Service)

Fajar, Dwi Junita, 2018. Pengaruh Intellectual Capital terhadap Produktivitas Dengan Employee Stock Option Plan (ESOP) sebagai Variabel Moderasi pada Perbankan Fitz-Enz, Jac.2000 .ROI of Human Capital: Measuring Attitudes and Managerial "Succes". Personel Psychology, 127-143

Gaol, Jummy L. Human Capital Manajemen Sumber Daya Manusia. 2014. Penerbit PT. Gramedia Widiasarana Indonesia. Jakarta.

Indriantoro, Nur \& Bambang Supomo. 1999. Metodologi Penelitian Bisnis Untuk Akuntansi $\mathcal{E}$ Managemen. Edisi Pertama. Yogyakarta: BPFE.

Kock,N. (2017). WarpPLS User Manual Version 6.0 Laredo, Texas: ScriptWarp System Maghfiroh, Siti. 2010. Pengaruh Sistem Akuntansi Manajemen, Sistem Informasi Manajemen dan Intellectual Capital dalam memoderasi hubungan antara Implementasi TQM dengan Kualitas Jasa Pendidikan dan Implikasinya terhadap Kinerja Perguruan Tinggi. Desertasi. Program Pascasarjana. Universitas Padjadjaran. Bandung.

Mahmudi, 2010. Manajemen Kinerja Sektor Publik. Edisi Kedua. Unit Penerbit dan Percetakan STIE YKPN. Yogyakarta

Mardiasmo, 2009. Akuntansi Sektor Publik. Penerbit Andi. Yogyakarta

Peraturan Menteri Dalam Negeri Nomor 59 Tahun 2007 tentang Pedoman Pengelolaan Keuangan Daerah, Perubahan atas Peraturan Menteri Dalam Negeri Nomor 13 tahun 2006

Sedarmayanti, 2011. Manajemen Sumber Daya Manusia, Reformasi Birokrasi dan Manajemen Pegawai Negeri Sipil (cetakan kelima). Bandung: PT Refika

Sekaran, Uma (2000). Research Methods for Business. John Wiley \& Sons, Inc. $3^{\text {th }}$ edition.

Spencer, Lyle M and Signe M Spencer, (1993), Competence Work: Model For Superior Performance, John Wiley and Sons, Inc

Thamrin. 2006. New Public Management atau Bagaimana Good Governance bisa dicapai. http/kedai-kebebasan.org 